\title{
Future Projection of Droughts over South Korea Using Representative Concentration Pathways (RCPs)
}

\author{
Byung Sik Kim ${ }^{1}$, In Hyeok Park ${ }^{2}$, and Sung Ryong $\mathrm{Ha}^{2, *}$ \\ ${ }^{1}$ Department of Urban and Environmental Disaster Prevention Engineering, Kangwon National University, Gangwon-do, \\ Republic of Korea \\ ${ }^{2}$ Department of Urban Engineering, Chungbuk National University, Chungbuk, Republic of Korea
}

Received 18 July 2013, revised 2 March 2014, accepted 13 March 2014

\begin{abstract}
The Standardized Precipitation Index (SPI), a method widely used to analyze droughts related to climate change, does not consider variables related to temperature and is limited because it cannot consider changes in hydrological balance, such as evapotranspiration from climate change. If we were to consider only the future increase in precipitation from climate change, droughts may decrease. However, because usable water can diminish from an increase in evapotranspiration, it is important to research on projected droughts considering the amount of evapotranspiration along with projecting and evaluating potential droughts considering the impact of climate change. As such, this study evaluated the occurrence of droughts using the Standardized Precipitation Evapotranspiration Index (SPEI) as a newly conceptualized drought index that is similar to SPI but includes the temperature variability. We extracted simulated future precipitation and temperature data (2011 - 2099) from the Representative Concentration Pathway (RCP) climate change scenario of IPCC AR5 to evaluate the impact of future climate change on the occurrence of droughts of South Korea. We analyzed the ratio of evapotranspiration to precipitation of meteorological observatories nationwide. In addition, we calculated the SPEI related to drought in the process to evaluate the future occurrence of droughts of South Korea. To confirm validity of SPEI results, extreme indices were analyzed. This resulted in the notion that as we go further into the future, the precipitation increases. But because of an increase in evapotranspiration also from a rise in temperature and continued dryness, the severity of droughts is projected to exacerbate.
\end{abstract}

Key words: SPI, Evapotranspiration, SPEI, RCP climate change scenario

Citation: Kim, B. S., I. H. Park, and S. R. Ha, 2014: Future projection of droughts over South Korea using Representative Concentration Pathways (RCPs). Terr. Atmos. Ocean. Sci., 25, 673-688, doi: 10.3319/TAO.2014.03.13.01(Hy)

\section{INTRODUCTION}

Droughts cause very severe damages. However, unlike floods, it is not so easy to establish and take proper measures for a drought because its beginning and end cannot be exactly predicted and it has a wide impact on various parts of society as it progresses. According to the climate change projection, the precipitation is expected to increase in the East Asian region including South Korea and the dry seasons between the severe rainy seasons are also expected to get longer due to an increase in precipitation intensity and reduction in annual precipitation days. It is also projected that the evapotranspiration will increase according to increase in moisture demand in the air due to a rise in temper-

\footnotetext{
* Corresponding author

E-mail: simplet@cbnu.ac.kr
}

ature. If we see only the precipitation increase, the number of drought occurrences may decrease. However, as there is a possibility of decrease in usable water due to the increase in evapotranspiration, the drought projection research focusing on both precipitation and evapotranspiration changes, which are caused by climate change, is inevitable.

The $4^{\text {th }}$ IPCC (Intergovernmental Panel on Climate Change) report (2007) projected that the precipitation will increase in the regions located at $70^{\circ}$, or higher, north latitude and in polar region as well, whereas the subtropical region between $30^{\circ}$ north and south latitudes from the equator will be expanded and the precipitation will further decrease. The report also predicted that at least 1.7 billion of the world's population will suffer from water shortage in 2020s (average temperature of the earth will increase by $1^{\circ} \mathrm{C}$ ). According 
to "Climate Change Scenario 2011" of National Institute of Meteorological Research, the precipitation is expected to increase in the East Asian region including Korea, but at the same time, the dry seasons between the severe rainy seasons are also expected to get longer due to increase of precipitation intensity and reduction of annual precipitation days. It is also projected that the evapotranspiration will increase according to increase of moisture demand in the air due to a rise in temperature (NIMR 2011).

To analyze and manage the droughts, there have been many researches to quantify the drought severity by developing various drought indices which can analyze the drought severity and drought period using each different variable in each different area of interest (Du Pisani et al. 1998; Heim 2002; Keyantash and Dracup 2002). The representative drought indices include Palmer Drought Severity Index (PDSI; Palmer 1965), Soil Moisture Index (SMI), Standardized Precipitation Index (SPI; McKee et al. 1993), and Surface Water Supply Index (SWSI; Shafer and Dezman 1982), and as they have their own pros and cons, they are differently or comprehensively used after taking into account the hydrological and meteorological characteristics and water resource supply facilities in the region. We cannot say that a certain index is absolutely better than other indices. For instance, PDSI is widely used by the United States Department of Agriculture (USDA) to determine the urgent drought support but the PDSI has shown some weakness for mountainous terrain and areas of frequent climatic extremes (http://enso.unl.edu/ ndmc/enigma/indices.htm). As the western part of the U.S., which is the mountainous region, is likely to be influenced by regional weather, it is better to use the PDSI in mutually complementary relationship with the other indices such as SWSI that considered other conditions. The SPI can cover various periods on the basis of the precipitation probability in specific drought duration and it can project the drought in an early stage. People can easily understand the drought severity using this SPI, which is known to be less complicated than Palmer Index (NDMC: http://enso.unl.edu/ndmc).

The drought should be studied in comparison with average conditions, in other words, the normal conditions of water budget between the precipitation and evapotranspiration for a longer period of time to some extent in a specific area. However, in the process of SPI calculation, the variables associated with the temperature, which is not a precipitation variable, are not considered, and there is a growing concern about this (Mavromatis 2007; Kempes et al. 2008). For this reason, the Standardized Precipitation Evapotranspiration Index (SPEI), a newly conceptualized drought index that is similar to SPI but includes temperature variability, was recently developed.

As such, this study estimated the future drought using SPEI (Vicente-Serrano et al. 2010). First, in order to assess the impact of future climate change on drought occurrence in South Korea, this study analyzed the ratio of evapotrans- piration to precipitation using future precipitation and temperature data (2011 - 2099) simulated from Representative Concentration Pathways (RCPs) climate change scenario of IPCC AR5, and then projected the drought change. The second section of this paper deals with the necessity and theoretical background of the study and the third section proposes the limits of present drought indices and new methodologies. In the fourth section, SPEI application results are described and in the fifth section, the last chapter, the study results were summarized and discussed.

\section{THEORETICAL BACKGROUND}

\subsection{Limits of Present Drought Indices}

Traditionally, various drought indices were used for drought monitoring, and the representative ones include PDSI developed in the United States in the 1960s and SPI developed in the 1990s. SPI has an advantage of being able to use only the precipitation as input data, and it is widely used throughout the world after overcoming the defect of PDSI, which has difficulty in comparing other temporal and spatial indices, by providing standardized values of the relevant region through normalization. According to most climate change scenarios, the amount of future precipitation increases over South Korea (Sung et al. 2012). If we see only this result, the number of droughts can decrease but, still, there is a possibility of usable water decrease due to evapotranspiration increase by a rise in temperature over South Korea. Accordingly, if we are to assess and project the droughts, taking the impact of climate change into account, we must consider evapotranspiration.

PDSI considers the impact of evapotranspiration, including the temperature variable, to some extent, but the main shortcoming of the PDSI relates to its fixed temporal scale (between 9 - 12 months), and an autoregressive characteristic whereby index values are affected by the conditions up to four years in the past (Guttman 1998). Its greatest limit is that it requires the values of various variables such as 'available water capacity' of the soil and the calibration of the parameters is not available (Alley 1984). In order to overcome these defects, SPI, which uses only the precipitation as input data and makes the temporal and spatial comparison possible through the process of normalization, was developed (McKee et al. 1993). It is also being used all over the world. However, as SPI uses only the precipitation, it has a critical defect of being unable to consider the impact of evapotranspiration. As mentioned above, in the drought evaluation that considers climate change, the drought must be projected using the drought index that considers both the precipitation and evapotranspiration at the same time. To use SPI in drought change projection, we need two hypotheses. First, the precipitation variability in drought is larger than temperature and potential evapotranspiration (PET) variability. Second, temperature and potential evapotranspiration are 
stationary. However, many of the recent preceding researches raise the problems of the hypothesis that does not consider temperature-related variables (Abramopoulos et al. 1988; Hu and Willson 2000; Mavromatis 2007; Kempes et al. 2008). The preceding researches already made it clear that the rise in temperature is influencing the drought severity, and the outcome of future climate change models projects greater rise of temperature in the $21^{\text {st }}$ century (IPCC 2007). In these situations, Abramopoulos et al. (1988) suggested that about $80 \%$ of the precipitation will be lost by evapotranspiration and confirmed that the dryness by the rise in temperature is as important as the dryness by transpiration shortage. As mentioned above, many researches that project the rise in temperature give warning of the occurrence of severe droughts caused by evapotranspiration increase as much as the precipitation shortage (Sheffield and Wood 2008; Dubrovsky et al. 2009). Dubrovsky et al. (2009) also mentioned the impact of global warming simulated through a global model on the drought frequency and scale, suggesting that SPI has its own limits. For this reason, some researches recommend the use of PDSI that can consider temperature variable among various drought variables (Mavromatis 2007; Kempes et al. 2008). As previously mentioned, PDSI also has its own limits if it is to be used in connection with future climate changes, and the PDSI lacks the multi-scalar character essential for both assessing drought in relation to different hydrological systems, and differentiating among different drought types (http://sac.csic.es/spei/home.html).

SPEI used in this study, a drought index freshly suggested by climate change and drought fields recently, mutually complements the defects of SPI and PDSI. In other words, it can consider the variability of evapotranspiration caused by the changes in precipitation and temperature and it has the advantage of being able to classify the drought events according to time unit of precipitation shortage duration.

\subsection{Standardized Precipitation Evapotranspiration Index (SPEI)}

SPEI is calculated mostly in monthly unit and it shows the difference between precipitation and potential evapotranspiration. For calculation of potential evapotranspiration, the Thornthwaite model [Thornthwaite 1948; Thornthwaite and Mather 1955; Eq. (1)] is commonly used because the calculation is simple and most of all, monthly average temperature data can be easily obtained.

$$
P E T=16 K\left(\frac{10 T}{I}\right)^{m}
$$

Here, $T$ is monthly average temperature in ${ }^{\circ} \mathrm{C}$ unit, and $I$ is the yearly heat index obtained by adding up all monthly heat indices. Monthly heat index is obtained from Eq. (2) below.
$i=\left(\frac{T}{5}\right)^{1.514}$

Yearly heat index is obtained from the relationship between $I$ and $m$ variables, as shown in Eq. (3) below.

$$
m=6.75 E^{-7} I^{3}-7.71 E^{-5} I^{2}+1.79 E^{-2} I+0.492
$$

$K$ in Eq. (1) is the function of latitude and month, as shown in Eq. (4) below.

$$
K=\left(\frac{N}{12}\right)\left(\frac{N D M}{30}\right)
$$

Here, $N D M$ is the number of days in each month, and $N$ is the maximum value of daylight hours as shown in Eq. (5) below.

$N=\left(\frac{24}{\pi}\right) \varpi_{s}$

Here, $\varpi_{s}$ is sunrise time, which is obtained from Eq. (6) below.

$\varpi_{s}=\arccos (-\tan \phi \tan \delta)$

Here, $\phi$ is latitude and $\delta$ is solar declination, which can be obtained from Eq. (7) below.

$\delta=0.4093 \sin \left(\frac{2 \pi J}{365}-1.405\right)$

Here, $J$ is the number of monthly average Julian days.

SPEI is the difference between precipitation in a month $i$ and PET obtained above, as shown in Eq. (8) below (http:// sac.csic.es/spei/).

$D_{i}=P_{i}-P E T_{i}$

The calculated $D_{i}$ values are aggregated at different time scales, following the same procedure as for the SPI.

\section{RESULTS}

\subsection{Review of SPEI Performance}

As SPEI, which will be applied to future climate change scenario, was not used in as frequently in Korea, we need to compare it with present drought indices before full-scale application. Therefore, this study first compared the past drought simulation levels of SPEI and SPI. Using the monthly data from 60 observatories (Fig. 1) among all KMA observatories for a total of 39 years from 1973 - 2011, 
this study calculated the SPI and SPEI of drought events with six month duration in each observation point.

Table 1 below shows the historical drought rankings based on SPI and SPEI calculation results extracted from present reports for the past 13 drought events $(1976,1977$, 1978, 1981, 1982, 1988, 1994, 1995, 1997, 2000, 2001, 2002,2008 - 2009). SPI was in the order of 2000, 2008 2009, and 1988 drought and SPEI was in the order of 2000, 2008 - 2009, and 2001 drought.

The two indices show different $3^{\text {rd }}$ and $4^{\text {th }}$ ranking droughts. This study tried to find the reason. To find the causes of 1988 and 2001 droughts, this study analyzed the anomaly (this year-normal year) of temperature and pre- cipitation in 1987 winter [(Decembert, January, February (DJF)], 1988 spring [March, April, May (MAM)], 2000 DJF and 2001 MAM from that of normal years (Fig. 2). In Fig. 2, TMP means average temperature, TMX means maximum temperature, TMN means minimum temperature, and PRCP means precipitation. As the temperature was continuously dropping until just before the 1988 drought, the continuous precipitation decrease from 1987, not the evapotranspiration increase, is considered as the major cause of 1988 drought (Fig. 2a). The winter precipitation just before the drought from March to June of 2001 was rather more than normal years. But the average temperature of MAM in the early stage of drought was higher than normal years by
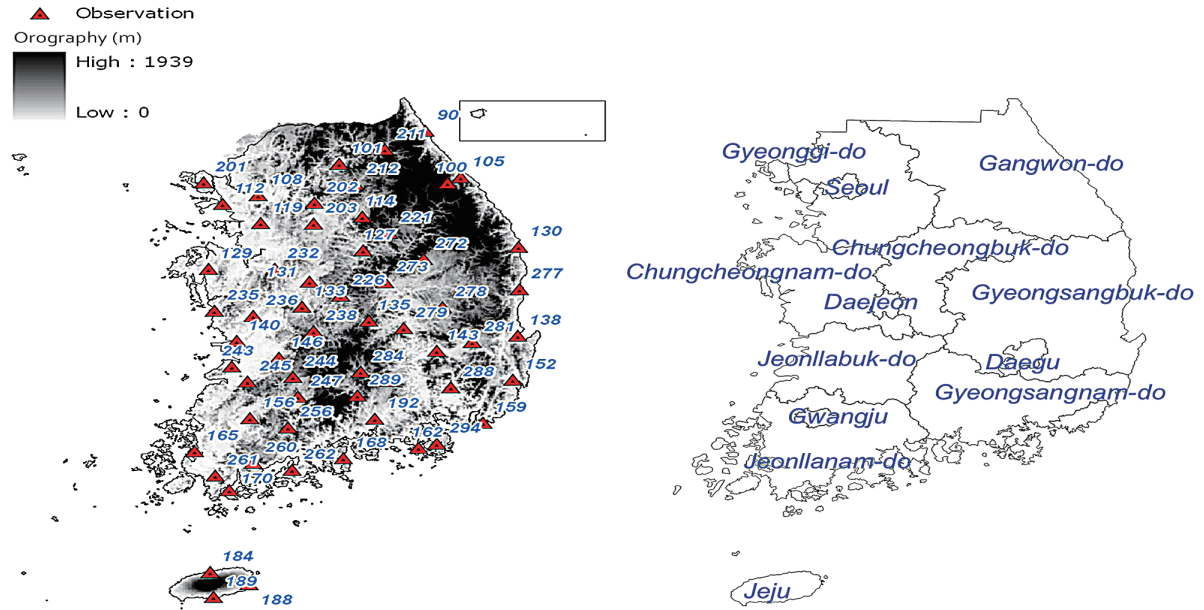

Fig. 1. Sixty observed stations used in this study and Altitude Distribution of South Korea (Kim et al. 2013).

Table 1. Historical Drought Rankings based on Drought Index (Kim et al. 2012).

\begin{tabular}{c|cc|cc}
\hline \multirow{2}{*}{ Drought Ranking } & \multicolumn{2}{|c|}{ SPI } & \multicolumn{2}{c}{ SPEI } \\
\cline { 2 - 5 } & Year & Value & Year & Value \\
\hline 1 & 2000 & -2.083 & 2000 & -1.897 \\
2 & $2008-2009$ & -1.596 & $2008-2009$ & -1.664 \\
3 & 1988 & -1.423 & 2001 & -1.429 \\
4 & 2001 & -1.394 & 1988 & -1.341 \\
5 & 1978 & -1.273 & 1978 & -1.286 \\
6 & 1981 & -1.184 & 1981 & -1.102 \\
7 & 1982 & -1.087 & 1994 & -0.983 \\
8 & 1994 & -0.916 & 1982 & -0.954 \\
9 & 2002 & -0.813 & 2002 & -0.877 \\
10 & 1995 & -0.776 & 1995 & -0.711 \\
11 & 1977 & -0.656 & 1977 & -0.684 \\
12 & 1976 & -0.234 & 1976 & -0.447 \\
13 & 1997 & 0.221 & 1997 & 0.192 \\
\hline
\end{tabular}



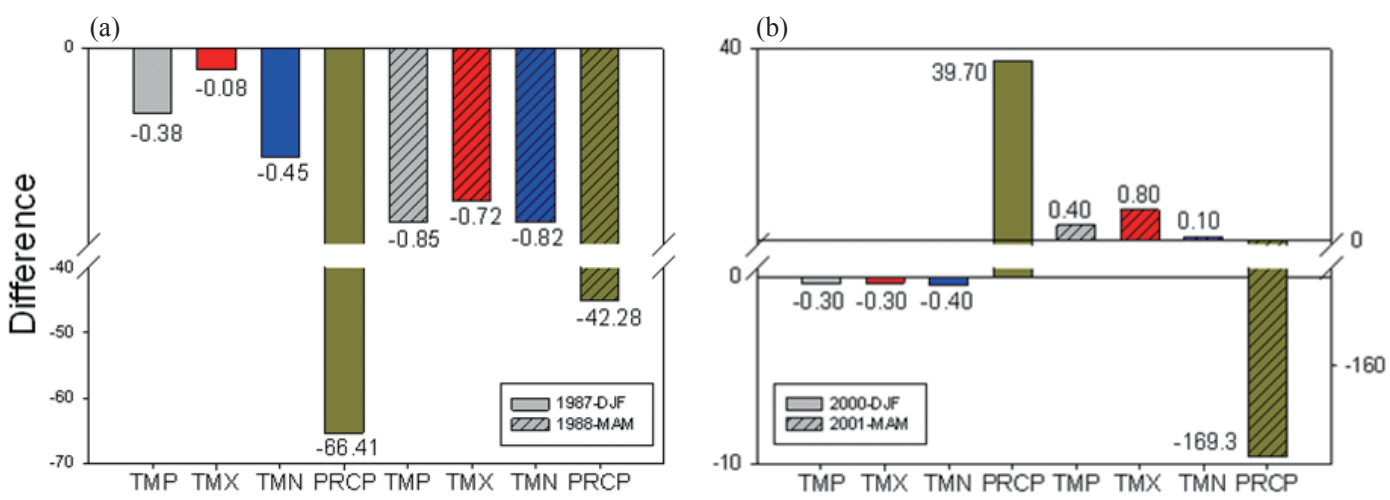

Fig. 2. Anomaly analysis (Kim et al. 2012). (a) 1987-DJF, 1988-MAM, (b) 2000-DJF, 2001-MAM.

$0.8^{\circ} \mathrm{C}$, which makes us guess that the temperature increase, rather than precipitation decrease, had effect on drought occurrence, after which the precipitation shortage in MAM further aggravated the drought (Kim et al. 2012). From this, we could get a comparatively clearer understanding of the various fundamental problems that gave us difficulty in defining the drought.

Through the comparison of drought indices for the past drought events, it was identified that the SPEI used in this study simulates the drought as nicely as SPI, and at the same time, it can detect the drought occurrence by temperature increase.

\subsection{Future Drought Project}

The future drought project data used in this study is the climate change scenario data over Korean Peninsula produced by KMA (Korea Meteorological Administration) after introducing regional climate model (HadGEM3-RA, Walters et al. 2011) of the U. K. Meteorological Agency, and the region covers some parts of China and Japan, with Korea at the center. The horizontal resolution of HadGEM3-RA is composed of $200 \times 180$ grids of $12.5 \mathrm{~km}$ distance in east-west direction and south-north direction, respectively, and the vertical resolution is composed of 38 layers from the ground to $40 \mathrm{~km}$ altitude. For lateral boundary buffering grids where large-scale boundary conditions is provided, eight grid points at the most outer side of the model were used. For lateral boundary conditions, entire earth climate change project data in 6-hour interval was used. The entire earth climate change project data was also calculated using atmosphere-ocean-ice melting combined model (HadGEM2-AO, Collin et al. 2008) introduced by KMA from U. K. Meteorological Agency, and the horizontal grid distance was about $135 \mathrm{~km}$ (east-west direction $1.875^{\circ}$, south-north direction $1.25^{\circ}$ ). HadGEM3-RA is composed of past climate simulation (1950 - 2005) and future climate project data (2011 - 2099) based on RCP scenario (Sung et al. 2012). East Asian region, where Korea is located, has very complex geographical characteristics with great climate variability. So, in order to project the extreme climate events, detailed regional climate change scenario data with the horizontal resolution of more than several or tens of $\mathrm{km}$ is required (Boo et al. 2004, 2006; Im and Kwon 2007, Koo et al. 2009). Accordingly, for future extreme precipitation project for Korea, this study used the regional climate change scenario data of RCP8.5 produced in $12.5 \mathrm{~km}$ resolution HadGEM3-RA through bilinear interpolation to KMA observation points. Observation data analysis was conducted in a total of 60 points, where the current climate (1980 - 2005) and future climate (2011 - 2099) data were used.

To project the future climate compared to the current climate, this study used RCP8.5 project data which divided the future into three periods (future1: 2011 - 2040, future2: 2041 - 2070, future3: 2071 - 2099). RCP8.5 is a scenario assuming that no greenhouse gas mitigation policy is implemented, and it is an emission scenario corresponding to A2A1F1 of SRES.

\subsubsection{Projection of Precipitation and Evapotranspiration in South Korean Region}

Figures 3 and 4 show the monthly variability of average precipitation and evapotranspiration in the South Korean region in its future climate compared to its current climate. According to the figures, the farther we go into the future, the more the amount of precipitation and evapotranspiration increase. Though there are slight differences due to uncertainty of precipitation simulation itself, the precipitation was projected to generally increase as we go deep into the future further and further. However, more precipitation was projected in June, August, and September of the mid- $21^{\text {st }}$ century than the end of the $21^{\text {st }}$ century, because the rate of temperature increase of regional climate model decreases after the 2040s compared to entire earth climate model, which becomes more evident in RCP8.5 scenario than in RCP4.5 scenario. In particular, the average temperature in February and December at the end of the $21^{\text {st }}$ century was above freezing point, which produces or increases the 
evapotranspiration even in February and December.

Figure 5 shows the yearly variability of future climate change data. As we go into the future further and further, both the precipitation and evapotranspiration tend to increase, which means non-stationary. The evidence of non-stationary is revealed more clearly in temperature because the climate model has high degree of accuracy and skillfulness in temperature simulation. The rates of increase in precipitation and evapotranspiration showed similar values but the ratio of evapotranspiration to precipitation got higher and higher as we go deeper in the future. The ratio was higher than $70 \%$ at the end of the $21^{\text {st }}$ century. The evapotranspiration increase in this period indicates the increase of possibility of drought occurrence. Accordingly, the latter part of this study also projected the future droughts in the South Korean region.

\subsubsection{Projection of Extreme Droughts in South Korean Under Climate Change}

Figure 6 shows the SPEI in current based on 6-month duration. According to the figure, the severe droughts are occurring on an approximate 4-year frequency in current climate. According to SPEI in future climate (Fig. 7), it was projected that the further we go into the future, the more frequently the droughts with great intensity will occur. In particular, it was projected that the risks of droughts with great intensity will increase more at the end of the $21^{\text {st }}$ century than in mid- $21^{\text {st }}$ century because the amount of evapotranspiration increases at the end of the $21^{\text {st }}$ century.

To quantitatively examine the frequency change, the spatial distribution of the frequency less than ' -1 ' was

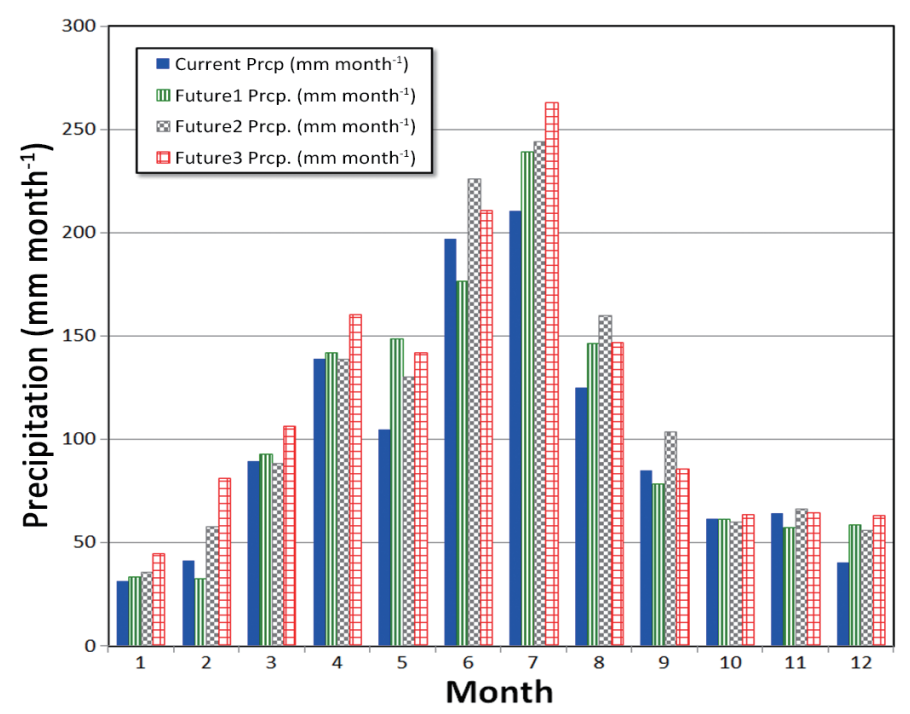

Fig. 3. Monthly changes of Precipitation (Kim et al. 2013).

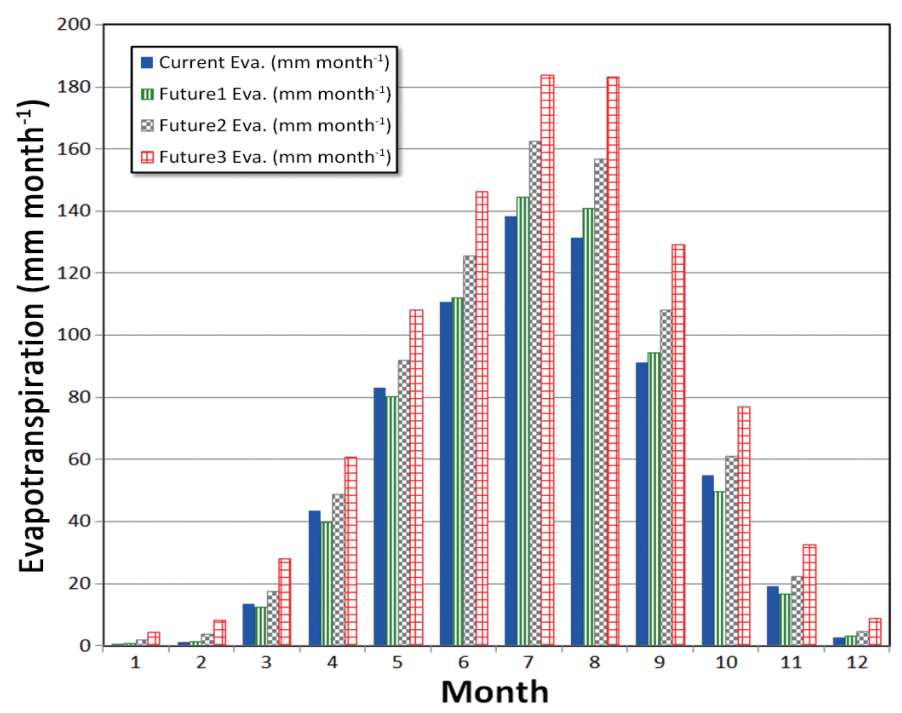

Fig. 4. Monthly changes of Evapotranspiration (Kim et al. 2013). 


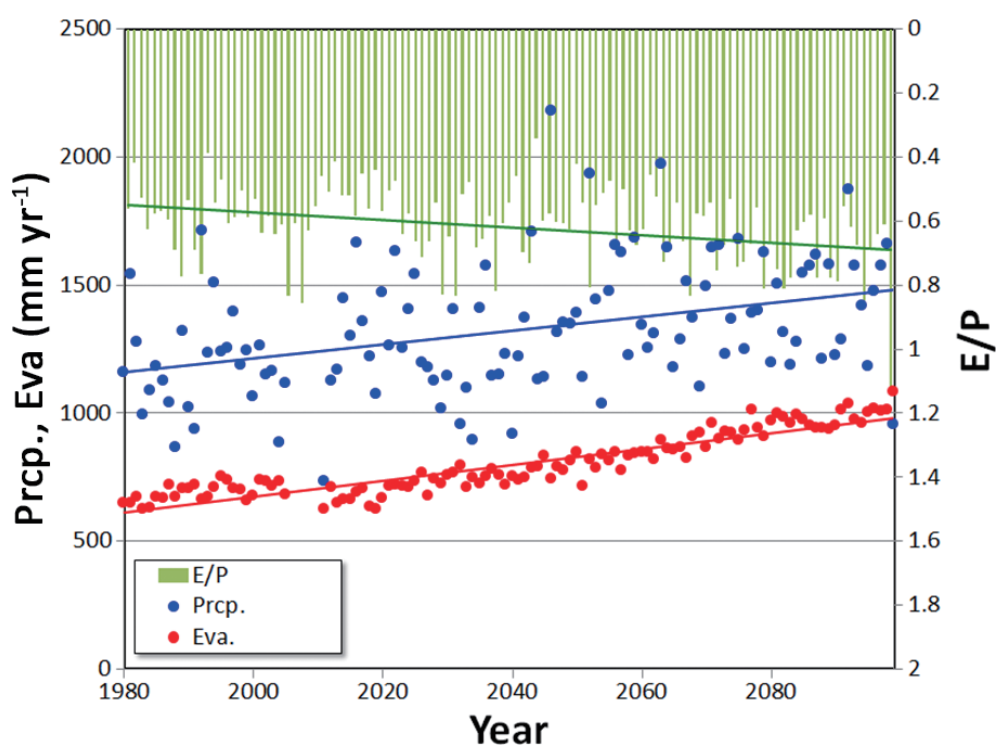

Fig. 5. Yearly changes of Precipitation and Evapotranspiration (Kim et al. 2013).

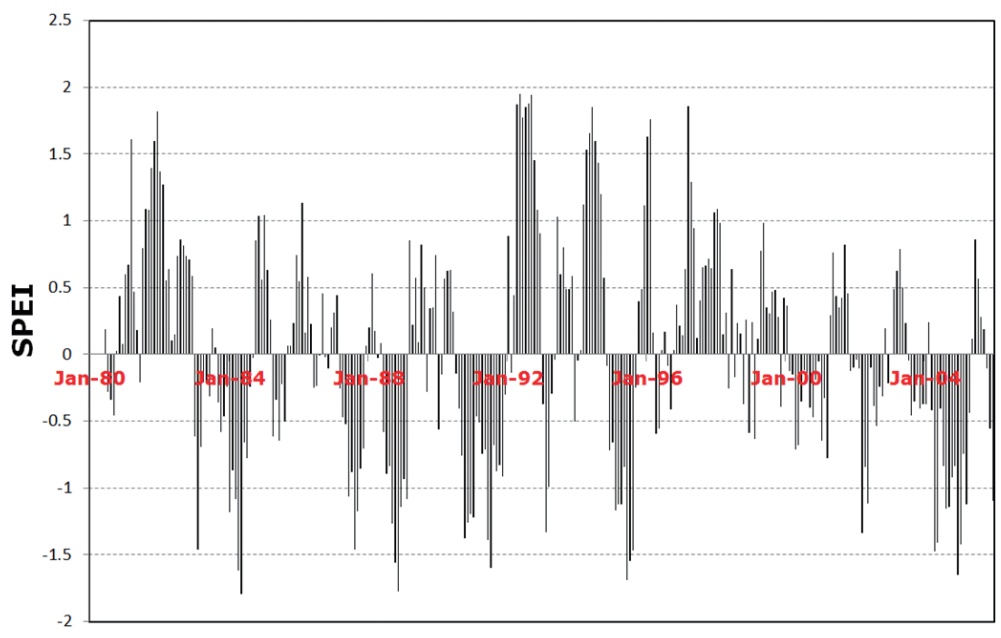

Fig. 6. SPEI in Current Climate (Kim et al. 2013).

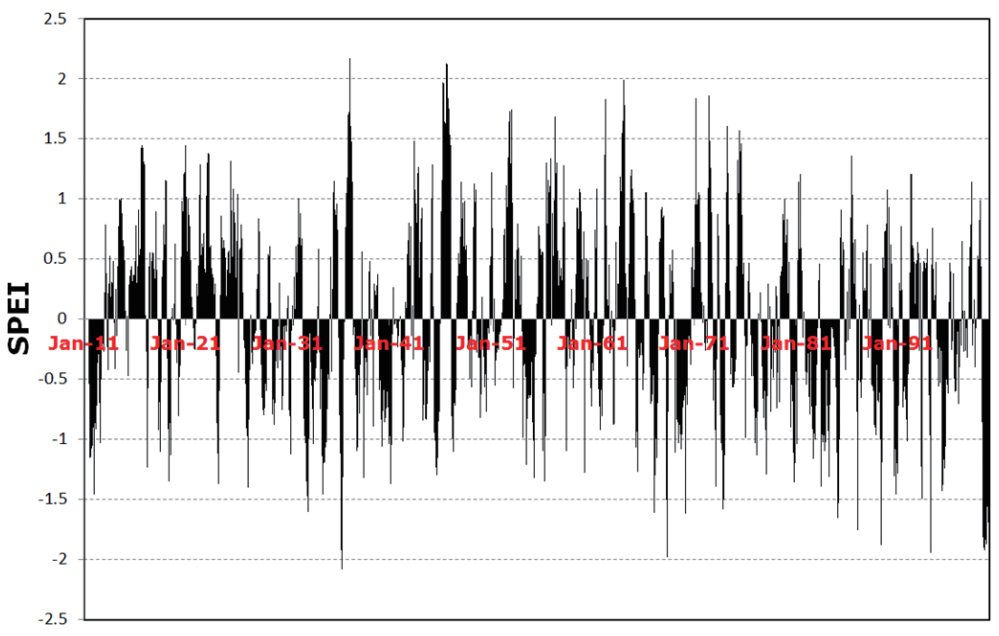

Fig. 7. SPEI under Future Climate (Kim et al. 2013). 
obtained for each season, except summer, from the present to future (Fig. 8). The reason for selecting '-1' is that the full-scale droughts occur when the SPEI value reaches '-1' or less after starting from ' 0 '. Non-stationary, which makes the future drought frequency generally higher than current frequency, was also identified. In current climate, the metropolitan regions, including Seoul, Jeonllanam-do, and Gyeongsangnam-do regions showed higher frequency, but at the end of the $21^{\text {st }}$ century, almost all regions except Jeonllanam-do region are exposed to drought risks. Especially, the inland region of Gyeongsangbuk-do showed comparatively higher frequency than other regions.

To quantitatively examine the drought magnitude, spatial distribution of SPEI in the spring, fall, and winter was derived (Figs. 9 - 11). Figures 9 - 11 show that the droughts get generally more severe as we go further into the future, and especially, that the drought size at the end of the $21^{\text {st }}$ century was significant, because the winter temperature from December to February at the end of the $21^{\text {st }}$ century is above freezing point, producing winter evapotranspiration. The fall and winter at the beginning of the $21^{\text {st }}$ century showed higher drought severity than in the mid- $21^{\text {st }}$ century, because the anomaly of the temperature in the beginning and middle part of the $21^{\text {st }}$ century is similar but the precipitation is higher in mid- $21^{\text {st }}$ century than the beginning of the $21^{\text {st }}$ century, as shown in Figs. 12 - 13. It was projected that the droughts with greater severity will occur in metropolitan and central inland regions during the spring season in the beginning of the $21^{\text {st }}$ century, and in the central and Jeonllanam-do regions during the winter season. During the springs in mid- $21^{\text {st }}$ century, the droughts in metropolitan region, some parts of Gangwon-do region, and Jeonllanam-do region, were of higher severity than other regions, and during the fall and winter seasons at the end of the $21^{\text {st }}$ century, generally all the regions were exposed to drought risks but the drought size was comparatively smaller in Jeonllanamdo region compared to other regions.

\subsubsection{Projection of Extreme Indices Related to Droughts}

This section aimed at extreme indices change related to drought in South Korea by using regional climate change scenarios and STARDEX extreme indices. Two extreme indices (longest dry period and frost day) were calculated. The longest dry period is the maximum number of consecutive dry days, and the frost day is number of frost days $\left(\mathrm{TMN}<0^{\circ} \mathrm{C}\right)$. Spatial distribution of extreme indices of the end of $21^{\text {st }}$ century (2070 - 2099) compared to the present (1981 - 2005) was analyzed by using precipitation and temperature data simulated by HadGEM3-RA.

Results showed that the longest dry period (DJF, MAM) was longest in Gyeongsangnam-do and Gyeongsangbuk-do. The frost day (DJF) was high nationwide except for southern coast area. Comparison of the observed data and current data of the RCP climate projection showed that projection data relatively well accord with the observed data (Figs. 14 - 15).

Future extreme indices were calculated by dividing future into the three following periods based on the RCP8.5 Scenario (future1: 2011 - 2040, future2: 2041 - 2070, future3: 2071 - 2099), and trend was compared and analyzed using regional averaged extreme indices. The longest dry period significantly increased in future 2, 3 compared to future1. The number of frost days decreased over whole period. Figure 16 shows that South Korea's number of dry days will increase and temperature will rise in future compared to the current due to climate change.

Change in linear slope of extreme indices on time of South Korea was investigated. If a slope value is more than 0 , the extreme indices increase by time, whereas if a slope value is less than 0 , the extreme indices decrease by time. Figure 17 represents increased and decreased distributions of extreme indices trend. Trend of the longest dry period greatly increased in the metropolitan area and central inland regions, whereas it decreased in Gangwon-do and the western coast area. For the frost day, its trend was expected to decrease nationwide (Fig. 17).

\section{DISCUSSION AND CONCLUSION}

Drought is a concept of considerably 'lower-than-normal (mean)' level of water availability that continues for a long time, which is difficult to express only in terms of precipitation. In other words, the drought should be considered in comparison with normal, the average condition of water budget between the precipitation and evapotranspiration during a longer period of time to some extent in a specific region (Kim et al. 2012). SPI is based on the assumption that the temperature and evapotranspiration do not change with time. However, the frequency and increase in tendency are being identified from the biannual change in the amount of potential evapotranspiration (Fig. 18) and the ratio of PET to the precipitation accounts for maximum 90\% (Fig. 19). Especially, this ratio is equivalent to the ratio at the time of drought occurrence. Accordingly, the loss of water due to evaporation or evapotranspiration should be considered in drought assessment.

In addition, not only the observation data but also various outcomes of climate change models project greater rise in temperature in the coming $21^{\text {st }}$ century (Fig. 20) and the considerable part of the precipitation will be connected to the loss by evapotranspiration, which makes it necessary to consider the evapotranspiration in projecting the droughts using the climate change scenario data. Accordingly, this study tried to verify whether SPEI, which can consider the evapotranspiration variability from the temperature variability, can well describe the drought like SPI, and to project the future drought over South Korean. 

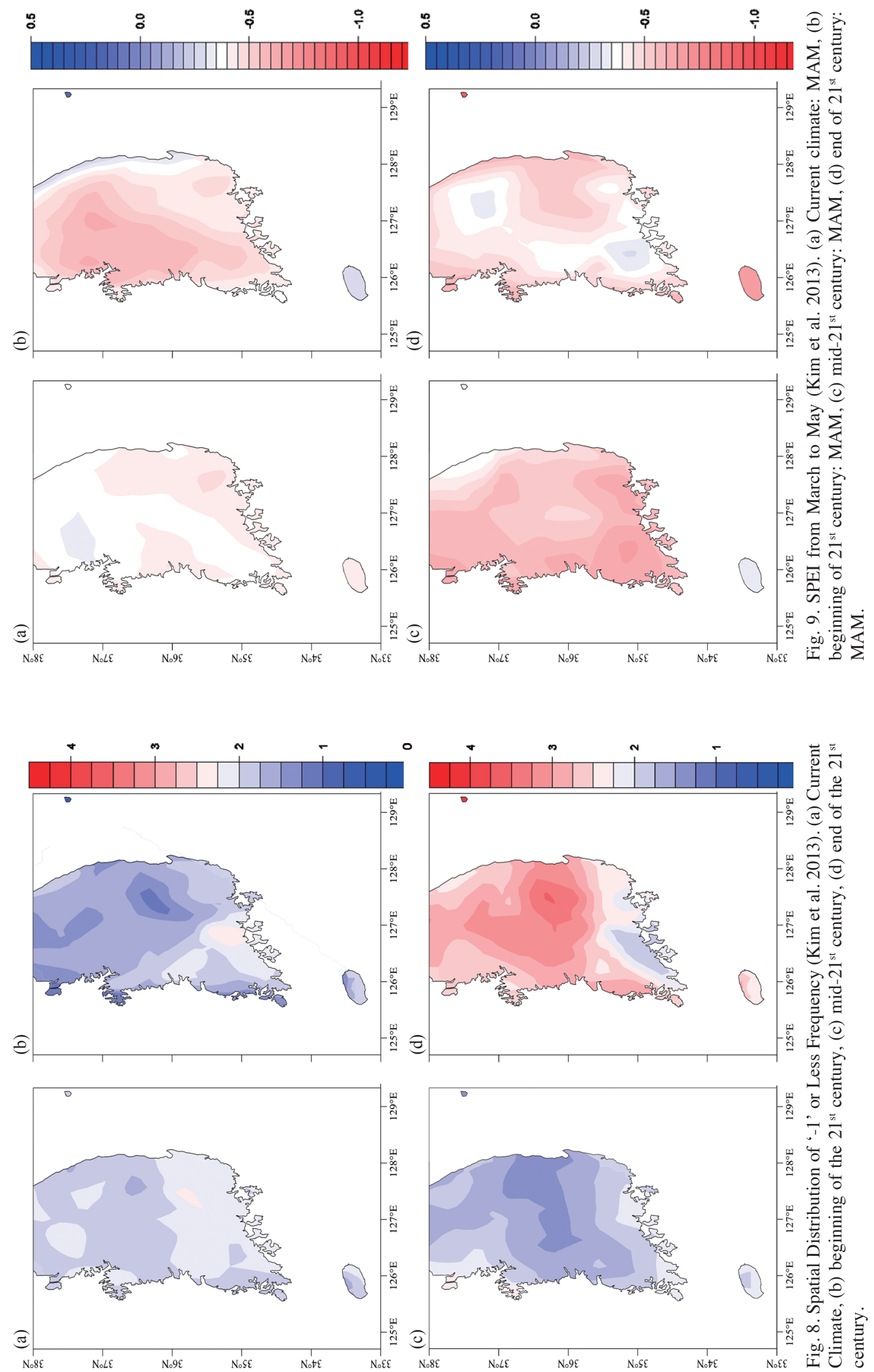

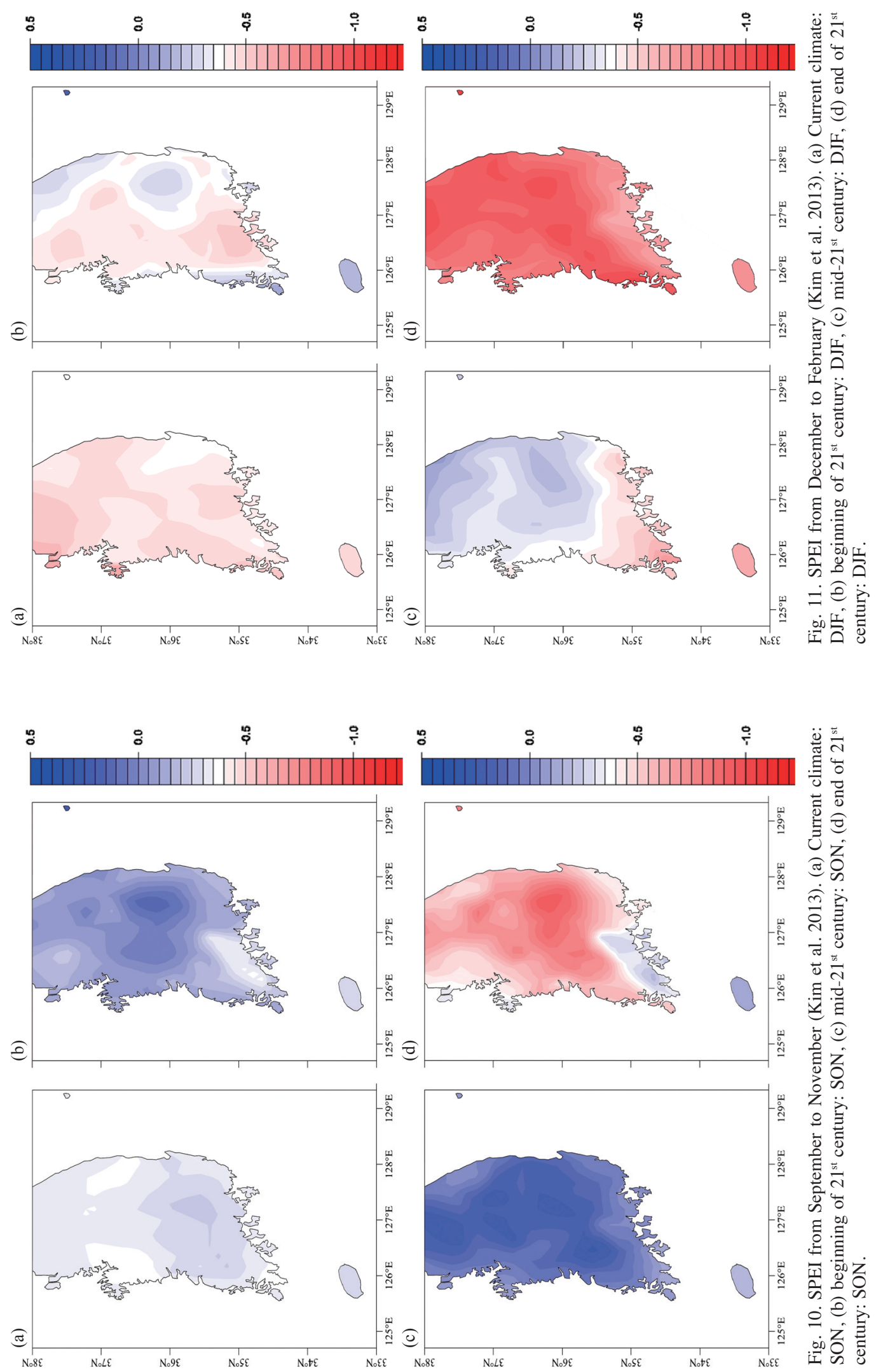

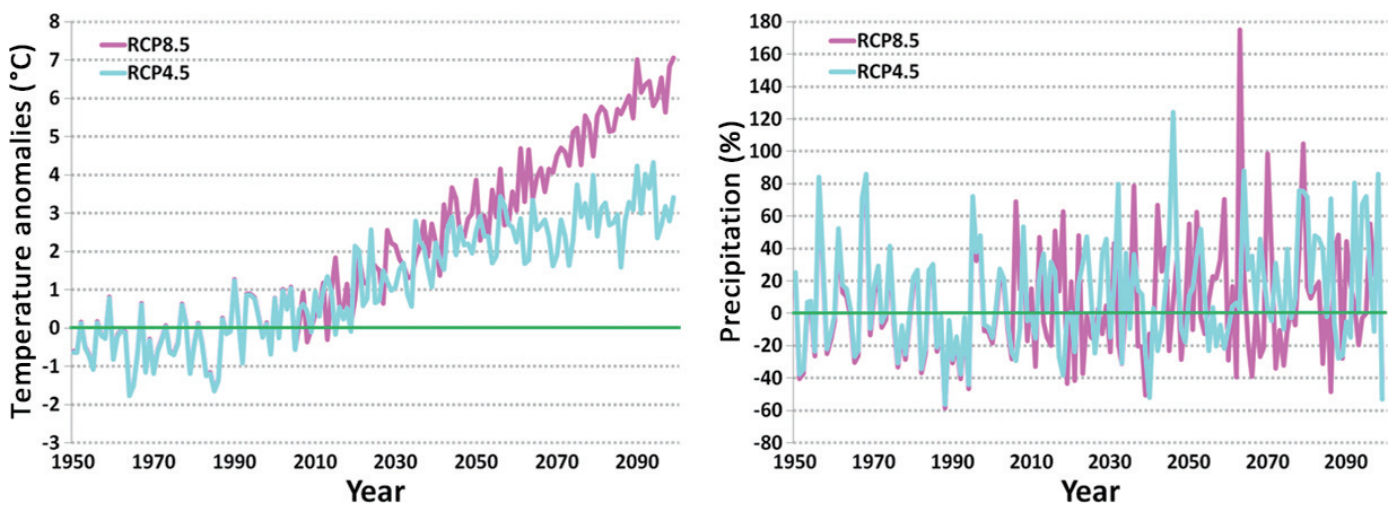

Fig. 12. Change of Fall Temperature (left) and Precipitation (right) in 1950 - 2099 compared to 1980 - 2009 (National Institute of Meteorological Research 2011).
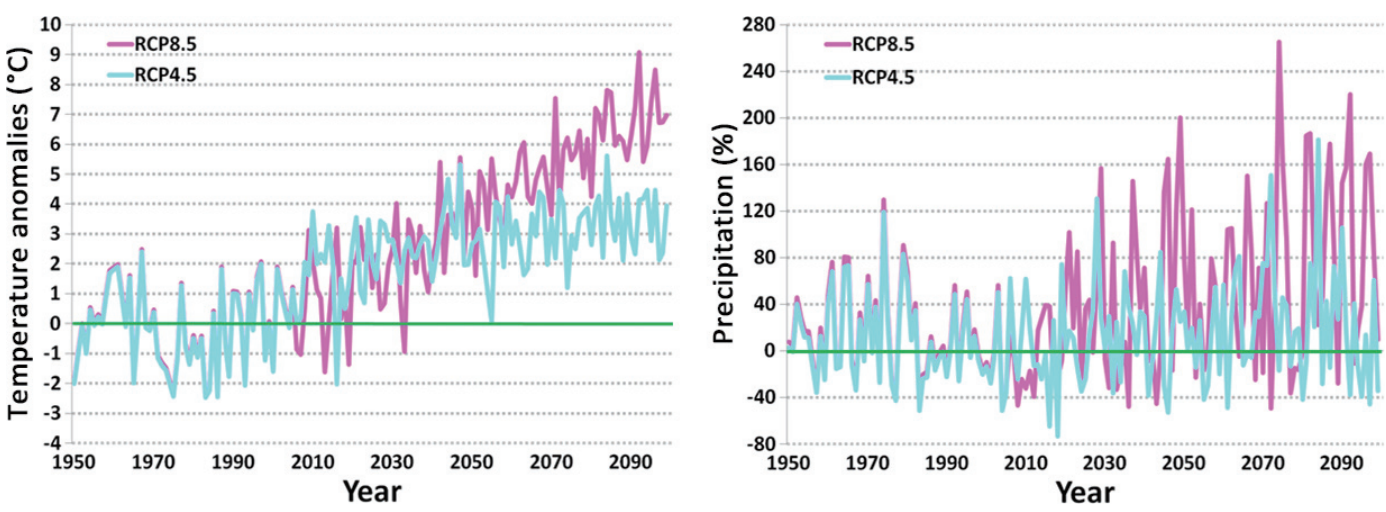

Fig. 13. Change of Winter Temperature (left) and Precipitation (right) in 1950 - 2099 compared to 1980 - 2009 (National Institute of Meteorological Research 2011).
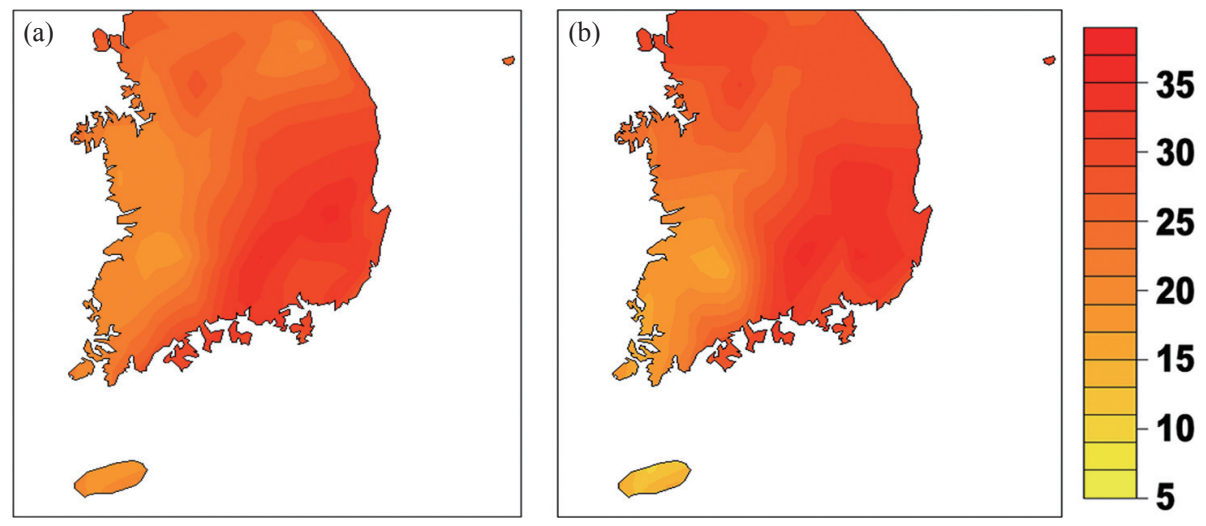

Fig. 14. Spatial distribution of extreme indices of observed and simulated under the current climate [longest dry period (days)]. (a) Observed, (b) simulated under the current climate. 

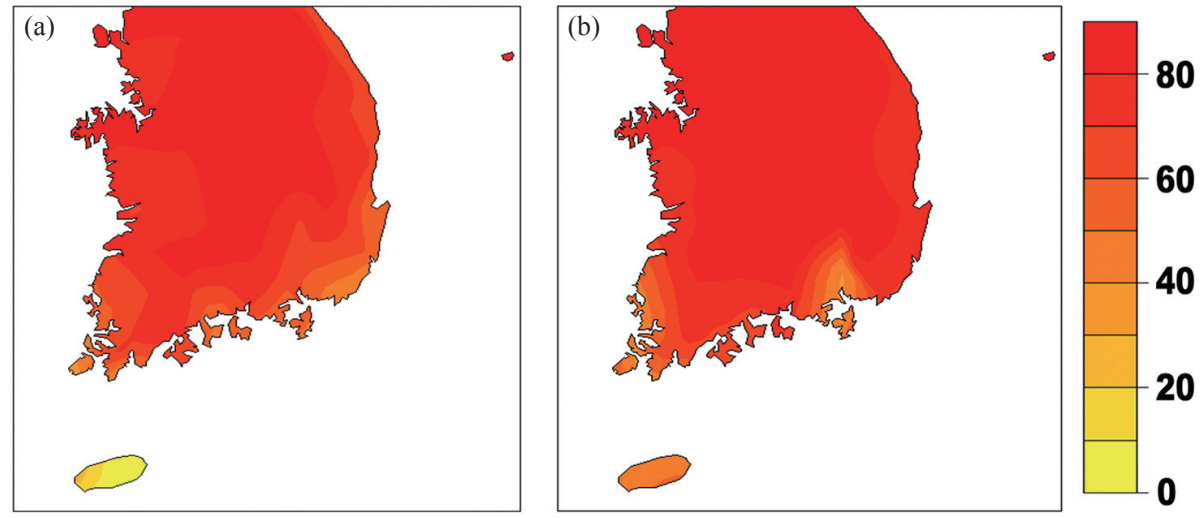

Fig. 15. Spatial distribution of extreme indices of observed and simulated under the current climate [frost day (days)]. (a) Observed, (b) simulated under the current climate.
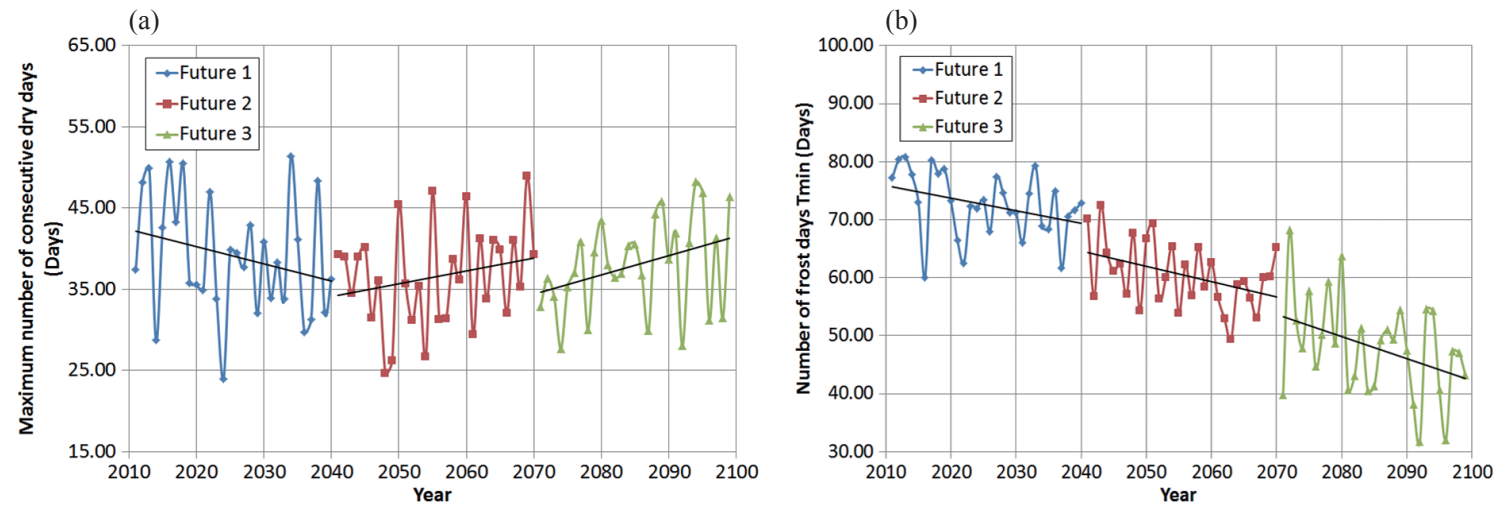

Fig. 16. Precipitation extreme indices tendency of future1 (2011 - 2040), future2 (2041 - 2070), future3 (2071 - 2099). (a) Longest dry period, (b) frost day.
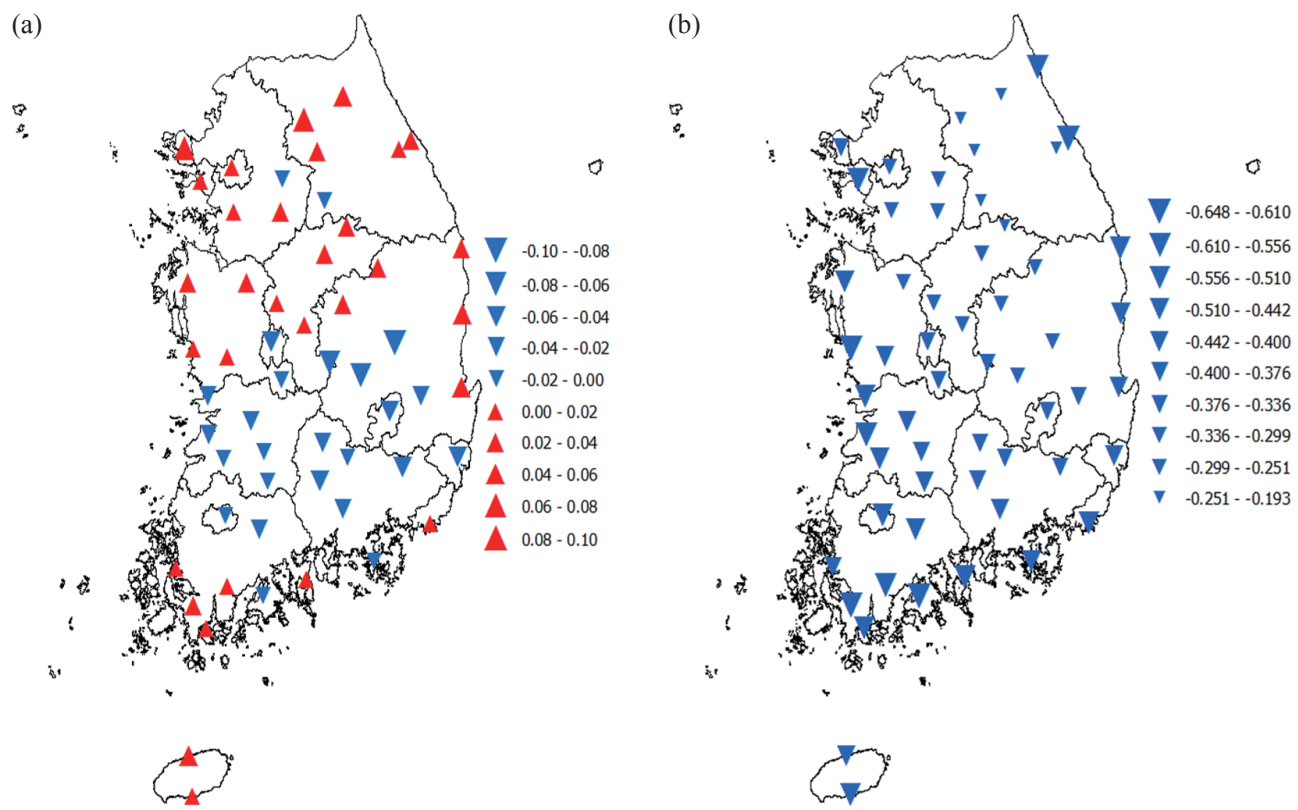

Fig. 17. Spatial distribution of trend. (a) Longest dry period, (b) frost day. 


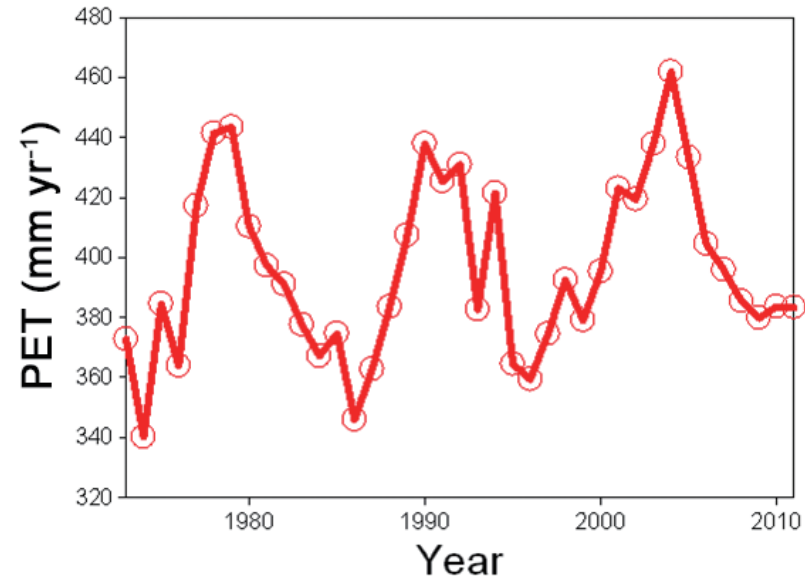

Fig. 18. Biannual Change in PET.

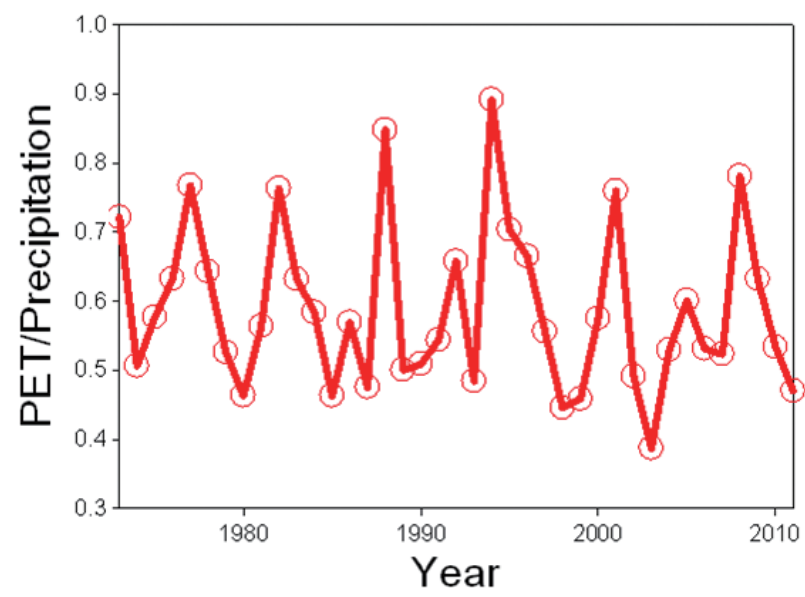

Fig. 19. Biannual Change in PET/Precipitation.

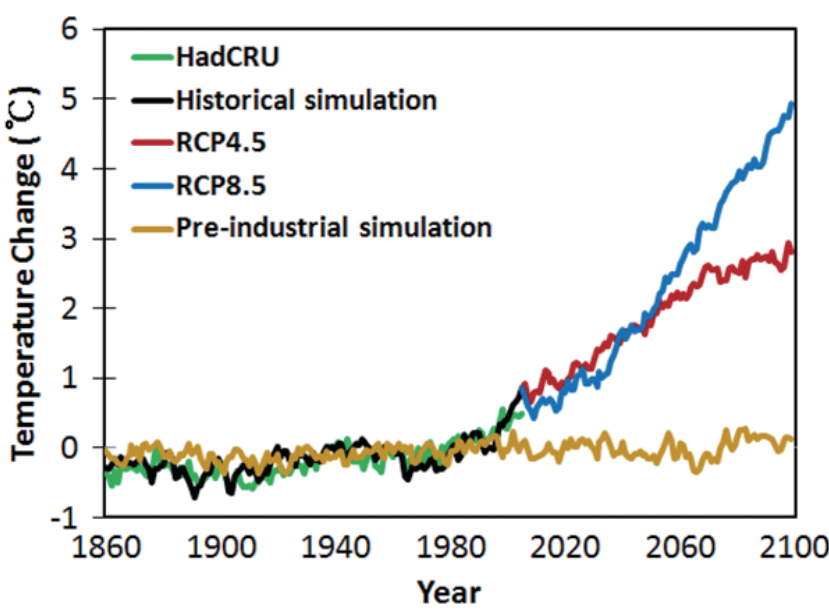

Fig. 20. $1.5 \mathrm{~m}$ temperature of 1860 - 2099 compared to 1971 - 2000 in the entire earth (National Institute of Meteorological Research 2011).
As there are not many cases where SPEI was applied to future climate change scenario in Korea, this study first compared the SPEI with existing drought indices prior to fullscale application. According to drought record survey report (Ministry of Construction and Transportation 2001), Korea experienced severe droughts in every 5 - 8 years for the recent 40 years, with slight and severe droughts occurring in the whole nation or in local regions in every $1-2$ years after the 1990s. As the result of drought frequency analysis in each basin using SPI, Lee et al. (2012) also identified that the droughts with 1 - 2 year or around 6-year frequency is statistically significant, and this result matched up well with the result of this study (Fig. 21).

Korea Environment Institute (2011) surveyed the causes, levels, and areas of the droughts that occurred after the 1970s. When the survey result was compared with SPEI result of this study, it was identified that SPEI well simulates the past drought levels and occurrence areas in the perspective of spatial distribution.

For drought projections under future climate change, many researches that combined the climate model with drought index were conducted (Ghosh and Mujumdar 2007; Loukas et al. 2008). Ghosh and Mujumdar (2007) evaluated the droughts in each 10-year interval and projected that the frequency of severe drought will increase, and Loukas et al. (2008) projected that the drought severity will increase at the end of the $21^{\text {st }}$ century rather than in mid- $21^{\text {st }}$ century. In domestic cases, Kim et al. (2011) projected the decrease of drought occurrence frequency due to precipitation increase at the beginning of the $21^{\text {st }}$ century, and the increase of drought occurrence frequency in inland areas and on the contrary, the decrease of drought occurrence frequency in coastal areas at the mid and end of the $21^{\text {st }}$ century. Also in this study, the number of occurrence frequency of SPEI less than '-1' increases as we go further into the future (Fig. 22), which indicates that our research results match up with previous research results comparatively well. In the aspect of drought size, SPEI and SPI showed equivalent values in the year with great possibility of drought occurrence (Figs. 22 - 23). However, as we go further into the future, SPEI showed more severity due to the impact of temperature increase. To confirm the validity of results, extreme indices were analyzed. From extreme indices related to drought it was found an increasing trend of the longest dry period and a decreasing trend the frost day, which is caused by rise in temperature of winter season. Thus, the hazard of drought due to increase in evapotranspiration in winter and spring seasons will increase.

This study can find its significance firstly in that new greenhouse gas scenario RCP climate change scenario was used in this study to contribute to the publication of IPCC $5^{\text {th }}$ climate change assessment report, and secondly, the drought index, which properly considered the supply (precipitation) and demand (evapotranspiration) in water budget, was used in this study. Conclusively, this study identified that the 


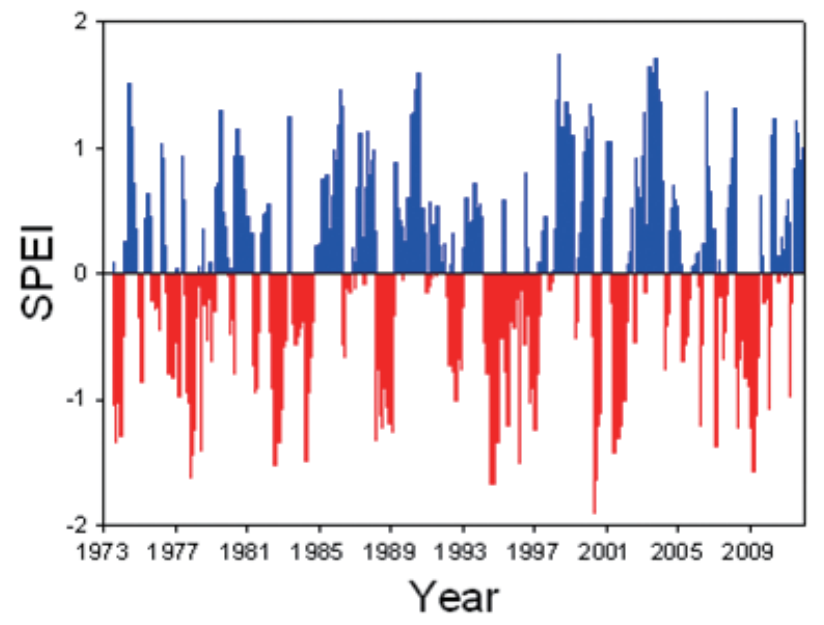

Fig. 21. SPEI for Average 6-Month Duration in South Korea.

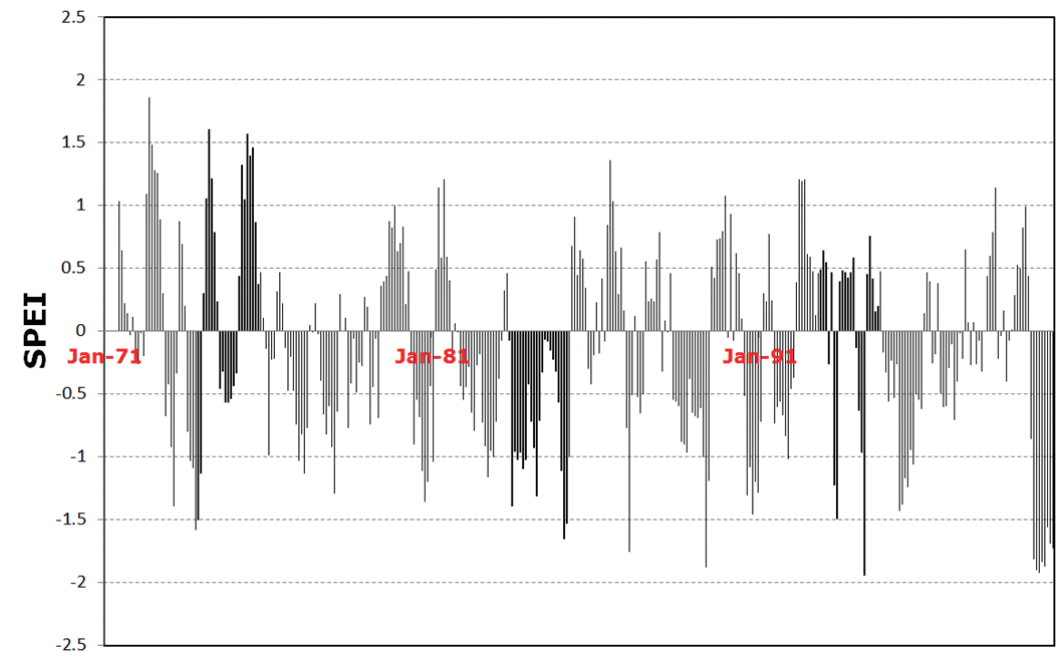

Fig. 22. SPEI at the End of the $21^{\text {st }}$ Century (2071 - 2099).

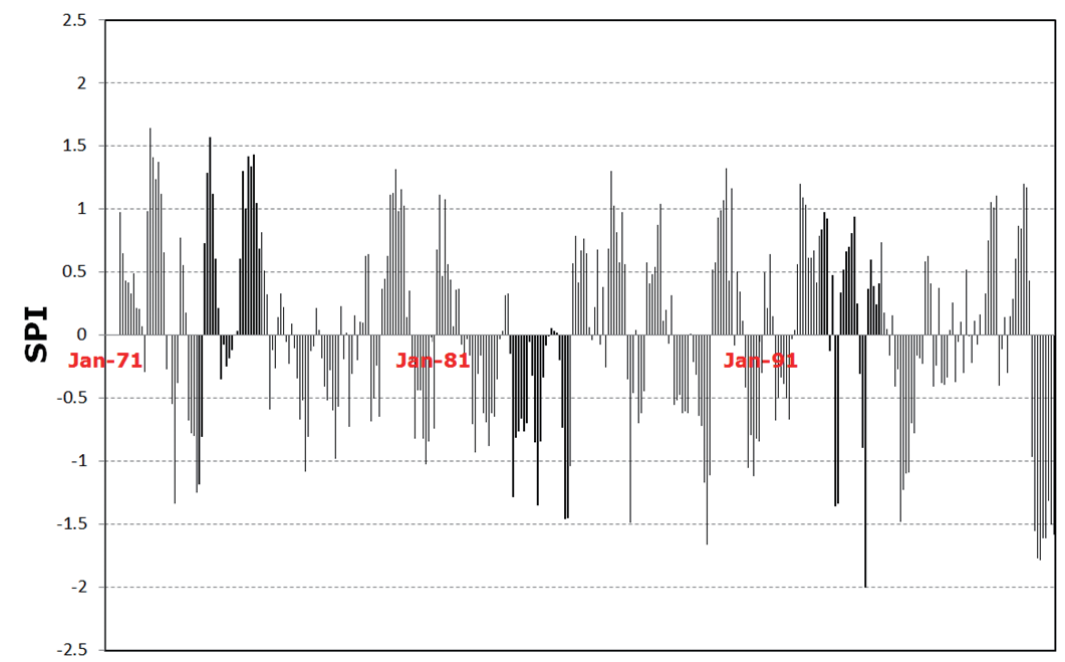

Fig. 23. SPI (2071 - 2099) at the End of the $21^{\text {st }}$ Century. 
regional climate model efficiently simulates the increase of severe droughts caused by future climate changes according to RCP, a new emission scenario.

Acknowledgments This research was supported by the National Research Foundation of Korea (NRF) under the Korean government [Ministry of Education and Science Technology (MEST)] in 2012 (No. 2011-0028914).

\section{REFERENCES}

Abramopoulos, F., C. Rosenzweig, and B. Choudhury, 1988: Improved ground hydrology calculations for global climate models (GCMs): Soil water movement and evapotranspiration.J.Climate, 1,921-941, doi: 10.1175/15200442(1988)001<0921:IGHCFG>2.0.CO;2. [Link]

Alley, W. M., 1984: The Palmer Drought Severity Index: Limitations and assumptions. J. Clim. Appl. Meteorol., 23, 1100-1109, doi: 10.1175/1520-0450(1984)023<11 00:TPDSIL $>2.0 . \mathrm{CO} ; 2$. [Link]

Boo, K. O., W. T. Kwon, J. H. Oh, and H. J. Baek, 2004: Response of global warming on regional climate change over Korea: An experiment with the MM5 model. Geophys. Res. Lett., 31, L21206, doi: 10.1029/2004GL021171. [Link]

Boo, K. O., W. T. Kwon, and H. J. Baek, 2006: Change of extreme events of temperature and precipitation over Korea using regional projection of future climate change. Geophys. Res. Lett., 33, L01701, doi: 10.1029/2005GL023378. [Link]

Collins, W. J., N. Bellouin, M. Doutriaux-Boucher, N. Gedney, T. Hinton, C. D. Jones, S. Liddicoat, G. Martin, F. O'Connor, J. Rae, C. Senior, I. Totterdell, S. Woodward, T. Reichler, and J. Kim, 2008: Evaluation of HadGEM2 model, Hadley Centre Technical Note 74, 47 pp.

Du Pisani, L. G., H. J. Fouché, and J. C. Venter, 1998: Assessing rangeland drought in South Africa. Agric. Syst., 57, 367-380, doi: 10.1016/S0308-521X(98)00024-9. [Link]

Dubrovsky, M., M. D. Svoboda, M. Trnka, M. J. Hayes, D. A. Wilhite, Z. Zalud, and P. Hlavinka, 2009: Application of relative drought indices in assessing climatechange impacts on drought conditions in Czechia. Theor. Appl. Climatol., 96, 155-171, doi: 10.1007/ s00704-008-0020-x. [Link]

Ghosh, S. and P. P. Mujumdar, 2007: Nonparametric methods for modeling GCM and scenario uncertainty in drought assessment. Water Resour. Res, 43, W07405, doi: 10.1029/2006WR005351. [Link]

Guttman, N. B., 1998: Comparing the Palmer Drought Index and the Standardized Precipitation Index. J. Am. Water Resour. Assoc., 34, 113-121, doi: 10.1111/j.17521688.1998.tb05964.x. [Link]

Heim, R. R.Jr., 2002: A review of twentieth-century drought indices used in the United States. Bull. Amer. Meteorol.Soc., 83, 1149-1165.

Hu, Q. and G. D. Willson, 2000: Effects of temperature anomalies on the Palmer Drought Severity Index in the central United States. Int. J. Climatol., 20, 1899-1911, doi: 10.1002/1097-0088(200012)20:15<1899::AIDJOC588>3.0.CO;2-M. [Link]

Im, E. S. and W. T. Kwon, 2007: Characteristics of extreme climate sequences over Korea using a regional climate change scenario. SOLA, 3, 17-20, doi: 10.2151/ sola.2007-005. [Link]

IPCC (Intergovernmental Panel on Climate Change), 2007: Climate Change 2007: The physical science basis. In: Solomon, S., D. Qin, M. Manning, Z. Chen, M. Marquis, K. B. Averyt, M. Tignor, and H. L. Miller (Eds.), Contribution of Working Group I to the Fourth Assessment Report of the Intergovernmental Panel on Climate Change, Cambridge University Press, Cambridge, United Kingdom, New York, 996 pp.

Kempes, C. P., O. B. Myers, D. D. Breshears, and J. J. Ebersole, 2008: Comparing response of Pinus edulis tree-ring growth to five alternate moisture indices using historic meteorological data. J. Arid. Environ., 72, 350-357, doi: 10.1016/j.jaridenv.2007.07.009. [Link]

Keyantash, J. and J. A. Dracup, 2002: The quantification of drought: An evaluation of drought indices. Bull. Amer. Meteorol. Soc., 83, 1167-1180.

Kim, B. S., H. H. Kwon, and H. S. Kim, 2011: Evaluation on impact of climate change on drought risk. Korean Wetl. Soc. J., 13, 1-11.

Kim, B. S., J. H. Sung, H. S. Kang, and C. H. Cho, 2012: Assessment of drought severity over South Korea using Standardized Precipitation Evapo-transpiration Index (SPEI). J. Korea Water Resour. Assoc., 45, 887900, doi: 10.3741/JKWRA.2012.45.9.887. [Link]

Kim, B. S., J. H. Sung, B. H. Lee, and D. J. Kim, 2013: Evaluation on the impact of extreme droughts in South Korea using the SPEI and RCP8.5 climate change scenario. J. KOSHAM, 13, 97-109, doi: 10.9798/ KOSHAM.2013.13.2.097. [Link]

Koo, G. S., K. O. Boo, and W. T. Kwon, 2009: Projection of temperature over Korea using an MM5 regional climate simulation. Clim. Res., 40, 241-248, doi: 10.3354/ cr00825. [Link]

Korea Environment Institute, 2011: The Present Water Resources and Impact Factors: Focusing on Climate Change, 154-342.

Lee, J. H., J. W. Seo, and C. J. Kim, 2012: Analysis on trends, periodicities and frequencies of Korean drought using drought indices. J. Korea Water Resour. Assoc., 45, 75-89, doi: 10.3741/JKWRA.2012.45.1.75. [Link]

Loukas, A., L. Vasiliades, and J. Tzabiras, 2008: Climate change effects on drought severity. Adv. Geosci., 17, 
23-29, doi: 10.5194/adgeo-17-23-2008. [Link]

Mavromatis, T., 2007: Drought index evaluation for assessing future wheat production in Greece. Int. J. Climatol., 27, 911-924, doi: 10.1002/joc.1444. [Link]

McKee, T. B., N. J. Doesken, and J. Kleist, 1993: The relationship of drought frequency and duration to time scales. Eighth Conference on Applied Climatology, 17-22 January 1993, California, Anaheim, 6 pp.

Ministry of Construction and Transportation, 2001: Drought Record Survey Repot, 341-342.

NIMR (National Institute of Meteorological Research), 2011: A Study on the Support and Use of Climate Change Project Technology (III), 73-74.

Palmer, W. C., 1965: Meteorological drought, Research paper No. 45, U.S. Weather Bureau.

Shafer, B. A. and L. E. Dezman, 1982: Development of a surface water supply index (SWSI) to assess the severity of drought conditions in snowpack runoff areas. $50^{\text {th }}$ Annual Western Snow Conference, Western Snow Conference, Nevada, Reno, 164-175.

Sheffield, J. and E. F. Wood, 2008: Projected changes in drought occurrence under future global warming from multi-model, multi-scenario, IPCC AR4 simulations. Climate Dyn., 31, 79-105, doi: 10.1007/s00382-0070340-z. [Link]
Sung, J. H., H. K. Kang, S. H. Park, C. H. Cho, D. H. Bae, and Y.O. Kim, 2012: Forecast of extreme precipitation in Korea at the end of the $21^{\text {st }}$ century based on RCP. Korean Meteorol. Soc., 22, 221-231.

Thornthwaite, C. W., 1948: An approach toward a rational classification of climate. Geogr. Rev., 38, 55-94, doi: 10.2307/210739. [Link]

Thornthwaite, C. W. and J. R. Mather, 1955: The water balance, Publications in Climatology, 8.

Vicente-Serrano, S. M., S. Beguería, and J. I. López-Moreno, 2010: A multiscalar drought index sensitive to global warming: The standardized precipitation evapotranspiration index. J. Climate, 23, 1696-1718, doi: 10.1175/2009JCLI2909.1. [Link]

Walters, D. N., M. J. Best, A. C. Bushell, D. Copsey, J. M. Edwards, P. D. Falloon, C. M. Harris, A. P. Lock, J. C. Manners, C. J. Morcrette, M. J. Roberts, R. A. Stratton, S. Webster, J. M. Wilkinson, M. R. Willett, I. A. Boutle, P. D. Earnshaw, P. G. Hill, C. MacLachlan, G. M. Martin, W. Moufouma-Okia, M. D. Palmer, J. C. Petch, G. G. Rooney, A. A. Scaife, and K. D. Williams, 2011: The met office unified model global atmosphere 3.0/3.1 and JULES global land 3.0/3.1 configurations. Geosci. Model Dev., 4, 1213-1271, doi: 10.5194/gmdd-4-1213-2011. [Link] 